BRAVZULIAN JOURNAL

OF MEDICAL AND BIOLOGICAL RESFARCH

www.bjournal.com.br
ISSN 0100-879X

Volume 44 (6) 497-605 June 2011

BIOMEDICAL SCIENCES

AND

CLINICAL INVESTIGATION

Braz J Med Biol Res, June 2011, Volume 44(6) 598-605

doi: 10.1590/S0100-879X2011007500048

Computed tomography assessment of lung structure in patients undergoing cardiac surgery with cardiopulmonary bypass

R.R. Rodrigues, A.Y. Sawada, J.-J. Rouby, M.J. Fukuda, F.H. Neves, M.J. Carmona, P. Pelosi, J.O. Auler and L.M.S. Malbouisson

The Brazilian Journal of Medical and Biological Research is partially financed by

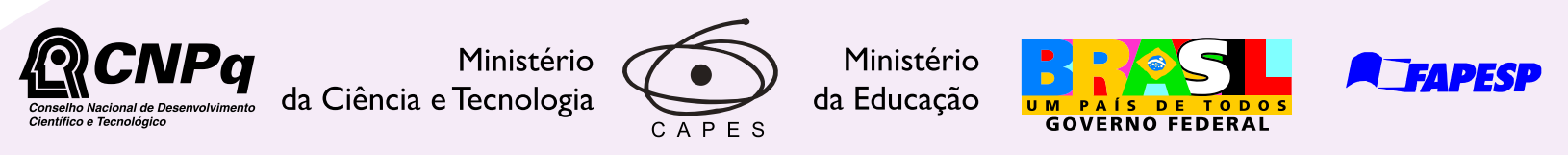

Institutional Sponsors
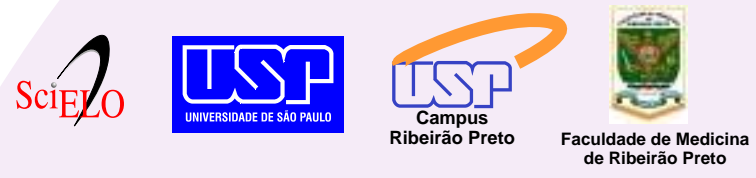
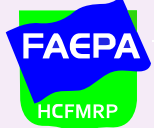

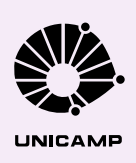

Ф SHIMADZU

GE Healthcare
Hotsite of proteomics metabolomics developped by:

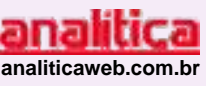

Thermo SCIENTIFIC 


\title{
Computed tomography assessment of lung structure in patients undergoing cardiac surgery with cardiopulmonary bypass
}

\author{
R.R. Rodrigues ${ }^{1}$, A.Y. Sawada ${ }^{1}$, J.-J. Rouby ${ }^{3}$, M.J. Fukuda ${ }^{1}$, F.H. Neves ${ }^{1}$, \\ M.J. Carmona ${ }^{1}$, P. Pelosi ${ }^{2}$, J.O. Auler ${ }^{1}$ and L.M.S. Malbouisson ${ }^{1}$ \\ ${ }^{1}$ Divisão de Anestesia, Hospital das Clínicas, Faculdade de Medicina, Universidade de São Paulo, \\ São Paulo, SP, Brasil \\ 2Dipartimento Ambiente, Salute e Sicurezza, Universita' degli Studi dell' Insubria, Varese, Italy \\ ${ }^{3}$ Multidisciplinary Intensive Care Unit, Department of Anesthesiology and Critical Care and Medicine, \\ La Pitié Salpetrière Hospital, University Pierre and Marie Curie, Paris, France
}

\begin{abstract}
Hypoxemia is a frequent complication after coronary artery bypass graft (CABG) with cardiopulmonary bypass (CPB), usually attributed to atelectasis. Using computed tomography (CT), we investigated postoperative pulmonary alterations and their impact on blood oxygenation. Eighteen non-hypoxemic patients (15 men and 3 women) with normal cardiac function scheduled for CABG under CPB were studied. Hemodynamic measurements and blood samples were obtained before surgery, after intubation, after CPB, at admission to the intensive care unit, and 12, 24, and $48 \mathrm{~h}$ after surgery. Pre- and postoperative volumetric thoracic CT scans were acquired under apnea conditions after a spontaneous expiration. Data were analyzed by the paired Student $t$-test and one-way repeated measures analysis of variance. Mean age was $63 \pm 9$ years. The $\mathrm{PaO}_{2} / \mathrm{FiO} 2$ ratio was significantly reduced after anesthesia induction, reaching its nadir after CPB and partially improving $12 \mathrm{~h}$ after surgery. Compared to preoperative CT, there was a $31 \%$ postoperative reduction in pulmonary gas volume $(P<0.001)$ while tissue volume increased by $19 \%(P<0.001)$. Non-aerated lung increased by $253 \pm 97 \mathrm{~g}(\mathrm{P}<0.001)$, from 3 to $27 \%$, after surgery and poorly aerated lung by $72 \pm 68 \mathrm{~g}(\mathrm{P}<0.001)$, from 24 to $27 \%$, while normally aerated lung was reduced by $147 \pm 119 \mathrm{~g}(\mathrm{P}<0.001)$, from 72 to $46 \%$. No correlations (Pearson) were observed between $\mathrm{PaO}_{2} / \mathrm{FiO}_{2}$ ratio or shunt fraction at $24 \mathrm{~h}$ postoperatively and postoperative lung alterations. The data show that lung structure is profoundly modified after CABG with CPB. Taken together, multiple changes occurring in the lungs contribute to postoperative hypoxemia rather than atelectasis alone.
\end{abstract}

Key words: Hypoxemia; Computed tomography; Coronary artery bypass graft; Cardiopulmonary bypass

\section{Introduction}

Respiratory dysfunction is one of the most frequent complications after coronary artery bypass graft (CABG) with cardiopulmonary bypass (CPB), even in the absence of previous pulmonary diseases (1). The prevalence of postoperative respiratory changes after CPB ranges from subclinical functional alterations in most of the patients to acute lung injury/acute respiratory distress syndrome in $2 \%$ of cases (2). In a previous study, we observed a $\mathrm{PaO}_{2} /$ $\mathrm{FiO}_{2}$ (arterial partial pressure of oxygen to inspired oxygen fraction) ratio lower than 200 in 250 of 461 postoperative patients after CPB (3).

Atelectasis leading to ventilation/perfusion mismatch has been proposed to be a major mechanism causing postoperative hypoxemia (4). Collapse of the lungs appears early after anesthesia induction and lasts several days after cardiac surgery and CPB (5-7). In an experimental pig model undergoing general anesthesia, CPB but not sternotomy induced marked atelectasis (4). Furthermore, the use of CPB doubled the risk of postoperative hypoxemia when compared to patients undergoing cardiac surgery without CPB (3), and the severity of postoperative hypoxemia is associated with an increase in the duration of postoperative mechanical ventilation (8).

Studies analyzing juxtadiaphragmatic computed tomog-

Correspondence: L.M.S. Malbouisson, Divisão de Anestesia, Hospital das Clínicas, FM, USP, Av. Enéas C. Aguiar, 255, 8ํandar, 05403-900 São Paulo, SP, Brasil. E-mail: malbouisson@hcnet.usp.br

Received August 27, 2010. Accepted March 16, 2011. Available online April 25, 2011. Published June 13, 2011. 
raphy $(\mathrm{CT})$ images reported that atelectasis compromised up to $20 \%$ of the lung area observed after CABG with CPB $(9,10)$, mainly in the dependent regions (11). In these studies, the CT section near the diaphragm was presumed to be representative of the entire lung. However, to our knowledge, no studies have evaluated the actual alterations in the entire pulmonary structure occurring in the overall lung.

The objectives of the present study were to describe the changes in lung structure and the increase in extravascular lung water (EVLW) contents occurring in the lungs of patients submitted to CABG with CPB determined by volumetric CT.

\section{Material and Methods}

The study was approved by the Ethics Committee (Comissão de Ética para Análise de Projetos de Pesquisa - CAPPesq - HCFMUSP - protocol No. 510/05) and all patients gave written informed consent to participate on the day before surgery. Eighteen patients with an indication of elective surgical treatment of coronary artery disease were enrolled. Inclusion criteria were: 1) coronary artery disease alone and 2) normal preoperative left ventricular function characterized by an ejection fraction greater than $55 \%$ measured by echocardiography or ventriculography. Exclusion criteria were: 1) history of chronic obstructive pulmonary disease with necessity of oxygen supplementation preoperatively; 2) preoperative pulmonary congestion; 3) intraoperative complications; 4) transfusion of more than 3 blood component units during surgery or in the immediate postoperative period, and 5) hemodynamic instability needing vasopressors or ventricular mechanical assistance on the first postoperative day.

On the day before surgery, a fast spiral thoracic CT scan (Toshiba Aquillion 16 CT scanner, Toshiba Medical Division, Japan) was obtained during a 15-s period of apnea at the end of a normal expiration. ECG, noninvasive arterial pressure, and pulse oxymetry were monitored during the acquisition using a Philips M3 transport monitor (Philips, Netherlands). A second CT was obtained under the same respiratory conditions on the first postoperative day, about 24 $h$ after arrival at the intensive care unit (ICU), when patients were extubated and breathing spontaneously.

\section{Preoperative patient care and hemodynamic and gasometric measurements}

General anesthesia was induced with fentanyl, etomidate and pancuronium and maintained by isoflurane inhalation associated with a supplementary bolus of fentanyl and pancuronium bromide. Standard operative monitoring consisted of electrocardioscopy, capnography, pulse oximetry, measurement of esophageal temperature, and invasive determination of arterial pressure. After induction of anesthesia, a fiberoptic thermodilution pulmonary artery catheter (CCO/SvO ${ }_{2}$ /VIPTMTD catheter, Edwards
Lifesciences, USA) was inserted for hemodynamic measurements. Tidal volume was set at $8 \mathrm{~mL} / \mathrm{kg}$ and the respiratory rate was adjusted to maintain $\mathrm{PaCO}_{2}$ values between 30 and $35 \mathrm{mmHg}$. An inspiratory time of $33 \%$ of the total respiratory cycle time and an inspired oxygen fraction of 0.60 were maintained throughout surgery. A positive endexpiratory pressure of $5 \mathrm{cmH}_{2} \mathrm{O}$ was set after intubation and maintained up to extubation in the ICU.

Aortic bicaval CPB was performed using an extracorporeal circuit and membrane oxygenator (Braile, Brazil) primed with $1500 \mathrm{~mL}$ lactated Ringer solution, $1 \mathrm{~g} / \mathrm{kg}$ manitol and 10,000 IU heparin. At initiation of CPB, ventilation was stopped to facilitate surgical exposure of intrathoracic structures. At the end of CPB, a $30-\mathrm{cmH}_{2} \mathrm{O}$ pressure was applied to the airways for $15 \mathrm{~s}$ to reverse lung collapse related to ventilatory pause and intrathoracic manipulation. Vasoactive drugs were infused when judged necessary by the attending anesthesiologist.

After arrival at the surgical ICU, patients were allowed to wake up and were extubated as soon as they presented one of the following conditions: 1) hemodynamic stability; 2) adequate pulmonary function (i.e., $\mathrm{PaO}_{2}>80 \mathrm{mmHg}$, and arterial partial pressure of carbon dioxide $\left[\mathrm{PaCO}_{2}\right]<45$ $\mathrm{mmHg}$ at $\mathrm{FiO}_{2} 0.4$, spontaneous respiratory rate $<30 / \mathrm{min}$, and tidal volume $>5 \mathrm{~mL} / \mathrm{kg}$ ); 3 ) consciousness (i.e., ability to follow simple commands), and 4) absence of surgical complications. After extubation, oxygen was supplemented to patients with a Venturi mask delivering a known quantity of oxygen. Respiratory and motor physical therapy treatment was instituted for all patients according to ICU routine. Noninvasive ventilation was not used in any of the patients after extubation.

Hemodynamic measurements were performed and arterial and venous blood samples were obtained after intubation, after CPB, at ICU admission, and 12 and $24 \mathrm{~h}$ after surgery according to the institutional standard care protocol. In addition, a baseline arterial blood sample was collected before anesthesia induction and after $48 \mathrm{~h}$. Intrapulmonary shunt was only computed at $24 \mathrm{~h}$ postoperatively, when postoperative CT was acquired.

\section{Analysis of volumetric CT images}

Lung scanning was performed from the apex to the diaphragm. The exposures were taken at $120 \mathrm{kV}$ and 250 $\mathrm{mAs}$. Contiguous $10-\mathrm{mm}$ thick axial sections were reconstructed from the volumetric data. The method to analyze volumetric CT images has been described elsewhere (12). Briefly, after delineating the external boundaries of both lungs in each CT section (Osiris 4.19, HUG, Switzerland), voxels contained in each region of interest were distributed into 1200 compartments according to their X-ray attenuation coefficient (CT number). Lung volume was computed as the total number of voxels $x$ voxel volume. The gas and tissue volumes and the weight were computed using the following equations: 1 ) volume of the voxel $=(\text { size of the pixel })^{2}$ 
$x$ section thickness; 2) total volume $=$ number of voxels $x$ volume of the voxel; 3 ) volume of gas $=(-C T$ number $/$ $1000) x$ total volume if the compartment considered has a CT number below 0 or volume of gas $=0$ if the compartment considered has a CT number above $0 ; 4$ ) volume of tissue $=(1+$ CT number / 1000) $x$ total volume if the compartment considered has a CT number below 0 or volume of tissue $=$ number of voxels $\mathrm{x}$ volume of the voxel if the compartment considered has a CT number above $0 ; 5$ ) weight of tissue $=$ volume of tissue if the compartment considered has a CT number greater than 0 or weight of tissue $=(1+$ CT number / 1000) $x$ volume of tissue if the compartment considered has a CT number below 0 .

Lung parenchyma was also analyzed according to aeration as follows: 1) overinflated (characterized by CT numbers between -1000 and -900 HU) (13); 2) normally aerated (CT numbers between -900 and $-500 \mathrm{HU}$ ) (12); 3) poorly aerated (CT numbers between -500 and $-100 \mathrm{HU}$ ), and 4) non-aerated (CT numbers between -100 and +100 HU) $(14,15)$.

\section{Statistical analysis}

Statistical analysis was performed using Aabel 2.4 (Gigawiz Inc., USA) and Graphpad Prism 4.02 (GraphPad Software, USA) softwares. Normal data distribution was tested by the Kolmogorov-Smirnov test. The temporal behavior of hemodynamics and of metabolic and blood gas parameters was analyzed by one-way repeated measures analysis of variance, followed by the Student-NeumannKeuls post hoc test when necessary. Comparisons between pre- and postoperative lung volumes and weight were performed using the paired Student $t$-test or Wilcoxon test. Correlations between CT scan-derived variables and physiological data were calculated by the Pearson test. All data are reported as means \pm SD or as described otherwise. The level of significance was fixed at $5 \%$.

\section{Results}

The individual preoperative characteristics of the 18 patients enrolled in the study are presented in Table 1. Mean age was $63 \pm 9$ years and mean weight was $82 \pm 24$ $\mathrm{kg}$. Mean surgery and CPB duration was $369 \pm 39$ and 93 \pm 23 min, respectively. All patients were extubated within $12 \mathrm{~h}$ of surgery, with the time to extubation being 435 \pm 182 min after arrival at the ICU. None of the patients developed respiratory failure after extubation or needed postoperative noninvasive ventilation. All patients were discharged from the ICU to the ward within $72 \mathrm{~h}$ without postoperative complications and from the hospital within 10 days after surgery.

\section{Effects of general anesthesia on gas exchanges and metabolic behavior}

Table 2 shows the hemodynamic data recorded throughout the study. Cardiac index was maintained above 2.5

Table 1. Individual preoperative characteristics of the patients.

\begin{tabular}{|c|c|c|c|c|c|c|c|c|c|c|}
\hline Subject & Age (years) & Weight (kg) & Height (cm) & LVEF (\%) & $\mathrm{Hb}(\mathrm{g} / \mathrm{dL})$ & $\mathrm{Cr}(\mathrm{g} / \mathrm{dL})$ & Reoperation & COPD & Hypertension & DM \\
\hline DRB & 48 & 66 & 162 & 62 & 14.7 & 0.9 & No & No & No & No \\
\hline MMF & 51 & 78 & 175 & 55 & 13.7 & 0.8 & No & Yes & Yes & Yes \\
\hline LFG & 62 & 112 & 185 & 50 & 12.9 & 1.3 & No & No & Yes & Yes \\
\hline JA & 77 & 70 & 170 & 73 & 14 & 1.1 & No & No & Yes & No \\
\hline RFFS & 65 & 90 & 171 & 70 & 13.7 & 0.9 & No & No & Yes & Yes \\
\hline OP & 58 & 72 & 170 & 57 & 14.5 & 1 & No & No & Yes & Yes \\
\hline ACPF & 62 & 81 & 170 & 50 & 14.6 & 0.8 & No & No & Yes & Yes \\
\hline ORC & 74 & 74 & 154 & 55 & 13 & 1.1 & Yes & No & Yes & No \\
\hline $\mathrm{AO}$ & 74 & 89 & 180 & 50 & 13.4 & 1.2 & No & No & Yes & Yes \\
\hline MNM & 62 & 75 & 165 & 78 & 13.5 & 0.9 & No & No & No & Yes \\
\hline DPC & 72 & 162 & 164 & 50 & 15.8 & 0.9 & No & No & Yes & No \\
\hline $\mathrm{MC}$ & 62 & 83 & 165 & 55 & 11.2 & 1.3 & Yes & Yes & Yes & No \\
\hline AJF & 71 & 72 & 172 & 60 & 14.9 & 1 & No & No & Yes & No \\
\hline JBM & 52 & 74 & 172 & 69 & 16.2 & 1.1 & No & No & Yes & No \\
\hline $\mathrm{JC}$ & 67 & 63 & 158 & 58 & 13.6 & 1 & No & No & Yes & No \\
\hline IS & 56 & 63 & 153 & 57 & 12.8 & 1.3 & No & No & No & No \\
\hline$A C$ & 73 & 70 & 167 & 70 & 15.9 & 1.2 & No & No & Yes & Yes \\
\hline GAT & 50 & 84 & 160 & 61 & 13.5 & 1.3 & No & No & Yes & No \\
\hline
\end{tabular}

$\mathrm{LVEF}=$ left ventricular ejection fraction; $\mathrm{Hb}=$ hemoglobin; $\mathrm{Cr}=$ serum creatinine; $\mathrm{COPD}=$ chronic obstructive pulmonary disease; $\mathrm{DM}$ $=$ diabetes mellitus. 
$\mathrm{L} \cdot \mathrm{min}^{-1} \cdot\left(\mathrm{m}^{2}\right)^{-1}$ and dobutamine $\left(8 \pm 3 \mu \mathrm{g} \cdot \mathrm{kg}^{-1} \cdot \mathrm{min}^{-1}\right)$ was initiated in 15 patients to facilitate weaning from CPB. Pulmonary artery pressure increased to slightly above normal values after $\mathrm{CPB}$, returning to baseline after admission to the ICU. Mean pulmonary artery occlusion pressure was lower than $18 \mathrm{mmHg}$ throughout the study.

A reduction in mixed venous saturation to values lower than $70 \%$ was observed from $12 \mathrm{~h}$ until the end of observation, as shown in Table 3. However, there was no clinical or hemodynamic evidence of low cardiac output state. Arterial lactate achieved highest values immediately after weaning from $\mathrm{CPB}$, returning to baseline $12 \mathrm{~h}$ postoperatively.

After intubation, the $\mathrm{PaO}_{2} / \mathrm{FiO}_{2}$ ratio significantly decreased, reaching its nadir after weaning from CPB, as shown in Figure 1. A significant improvement in $\mathrm{PaO}_{2} /$ $\mathrm{FiO}_{2}$ ratio was observed at $12 \mathrm{~h}$ postoperatively and was sustained up to the end of the observation period com- pared to the post-CPB measure. However, $\mathrm{PaO}_{2} / \mathrm{FiO}_{2}$ ratio values observed at 24 and $48 \mathrm{~h}$ were $22 \%$ lower than those measured in the awake state $(\mathrm{P}<0.05)$ when patients were breathing spontaneously, as shown in Figure 1. The mean intrapulmonary shunt value computed $24 \mathrm{~h}$ postoperatively was $13 \pm 5 \%$. No significant alterations in $\mathrm{PaCO}_{2}$ were observed throughout the study.

\section{Lung assessment by CT during the pre- and postoperative period}

Figure 2 shows representative CT slices of the lung apex, hilum and $2 \mathrm{~cm}$ above the diaphragm obtained preoperatively and on the first postoperative day. Overall lung volume was $3086 \pm 970 \mathrm{~mL}$ preoperatively, consisting of $71 \%$ gas volume $(2226 \pm 860 \mathrm{~mL})$ and $29 \%$ tissue volume $(862 \pm 180 \mathrm{~mL})$. The overall weight of the lung parenchyma was $863 \pm 180 \mathrm{~g}$. Non-aerated lung parenchyma weight

Table 2. Hemodynamic profile during surgery and during the first 24 postoperative hours.

\begin{tabular}{lcccccc}
\hline & After intubation & After CPB & ICU admission & ICU $12 \mathrm{~h}$ & ICU 24 h & P \\
\hline HR $(\mathrm{bpm})$ & $69 \pm 20$ & $98 \pm 17^{*}$ & $98 \pm 20^{*}$ & $95 \pm 16^{*}$ & $98 \pm 15^{*}$ & $<0.001$ \\
MAP $(\mathrm{mmHg})$ & $74 \pm 9$ & $66 \pm 8^{*}$ & $84 \pm 15$ & $76 \pm 9$ & $81 \pm 9$ & $<0.001$ \\
mPAP $(\mathrm{mmHg})$ & $25 \pm 6$ & $27 \pm 7$ & $25 \pm 7$ & $23 \pm 7$ & $23 \pm 6$ & $\mathrm{NS}$ \\
CVP $(\mathrm{mmHg})$ & $14 \pm 6$ & $16 \pm 6$ & $14 \pm 5$ & $11 \pm 4$ & $12 \pm 4$ & $\mathrm{NS}$ \\
PAOP $(\mathrm{mmHg})$ & $16 \pm 4$ & $17 \pm 5$ & $15 \pm 5$ & $14 \pm 5$ & $15 \pm 4$ & $\mathrm{NS}$ \\
$\mathrm{Cl}\left(\mathrm{L} \cdot \mathrm{min}^{-1} \cdot\left(\mathrm{m}^{2}\right)^{-1}\right)$ & $2.5 \pm 0.8$ & $3.9 \pm 1.4^{*}$ & $3.2 \pm 1.1^{*}$ & $3.3 \pm 0.9^{*}$ & $3.9 \pm 0.7^{*}$ & 0.003 \\
SI $\left(\mathrm{mL} \cdot \mathrm{beat}^{-1} \cdot\left(\mathrm{m}^{2}\right)^{-1}\right)$ & $38 \pm 12$ & $40 \pm 13$ & $34 \pm 13$ & $35 \pm 11$ & $41 \pm 10$ & $\mathrm{NS}$ \\
SVRi $\left(\right.$ dyn $\left.\cdot \mathrm{s} \cdot \mathrm{cm}^{-5} \cdot\left(\mathrm{m}^{2}\right)^{-1}\right)$ & $2090 \pm 667$ & $1255 \pm 627^{*}$ & $1944 \pm 676$ & $1707 \pm 442^{*}$ & $1499 \pm 323^{*}<0.001$ \\
PVRi $\left(\right.$ dyn $\left.\cdot \mathrm{s} \cdot \mathrm{cm}^{-5} \cdot\left(\mathrm{m}^{2}\right)^{-1}\right)$ & $312 \pm 220$ & $225 \pm 158$ & $239 \pm 129$ & $241 \pm 124$ & $168 \pm 93$ & $\mathrm{NS}$ \\
\hline
\end{tabular}

Data are reported as means $\pm \mathrm{SD}$. $\mathrm{CPB}=$ cardiopulmonary bypass; ICU = intensive care unit; HR = heart rate; $\mathrm{MAP}=$ mean arterial pressure; $\mathrm{mPAP}=$ mean pulmonary artery pressure $\mathrm{CVP}=$ central venous pressure; $\mathrm{PAOP}$ = pulmonary artery occlusion pressure; $\mathrm{Cl}=$ cardiac index; $\mathrm{SI}$ = systolic index; SVRi = systemic vascular resistance index; PVRi = pulmonary vasculary resistance index; $\mathrm{NS}=$ nonsignificant. ${ }^{*} \mathrm{P}<0.05$ compared to the time after intubation (one-way ANOVA for repeated measures).

Table 3. Gas exchange and metabolic profile during surgery and during the first 48 postoperative hours.

\begin{tabular}{lcccccccc}
\hline & Awake & After intubation & After CPB & ICU admission & ICU $12 \mathrm{~h}$ & ICU $24 \mathrm{~h}$ & ICU 48 h & P \\
\hline $\mathrm{PaCO}_{2}(\mathrm{mmHg})$ & $38 \pm 5$ & $35 \pm 5$ & $38 \pm 5$ & $40 \pm 7$ & $35 \pm 4$ & $37 \pm 4$ & $38 \pm 5$ & $\mathrm{NS}$ \\
Arterial $\mathrm{pH}$ & $7.44 \pm 0.05$ & $7.43 \pm 0.05$ & $7.33 \pm 0.08^{*}$ & $7.33 \pm 0.07^{*}$ & $7.38 \pm 0.04$ & $7.4 \pm 0.05$ & $7.39 \pm 0.05$ & 0.001 \\
Base excess $(\mathrm{mEq} / \mathrm{L})$ & $0.1 \pm 1.4$ & $0 \pm 1.6$ & $-4.5 \pm 3.3^{*}$ & $-4.2 \pm 4.05^{*}$ & $-3 \pm 2^{*}$ & $-0.9 \pm 2.4$ & $-0.7 \pm 2.1$ & 0.003 \\
Arterial lactate $(\mathrm{mg} / \mathrm{dL})$ & $13 \pm 3$ & $14 \pm 3$ & $36 \pm 20^{*}$ & $35 \pm 26^{*}$ & $19 \pm 7$ & $16 \pm 6$ & $14 \pm 6$ & 0.004 \\
$\mathrm{PvCO}_{2}-\mathrm{PaCO}$ & - & $5 \pm 2$ & $3 \pm 4$ & $4 \pm 5$ & $4 \pm 4$ & $2 \pm 3$ & $5 \pm 4$ & $\mathrm{NS}$ \\
$\left(\mathrm{mmHg}_{2}\right.$ & - & $80 \pm 6$ & $78 \pm 10$ & $74 \pm 11$ & $65 \pm 9^{+}$ & $69 \pm 7^{+}$ & $65 \pm 9^{+}$ & 0.004 \\
$\mathrm{SvO}_{2}(\%)$ & - & & & & & & & \\
\hline
\end{tabular}

Data are reported as means $\pm \mathrm{SD}$. $\mathrm{CPB}=$ cardiopulmonary bypass; $\mathrm{ICU}=$ intensive care unit; $\mathrm{PaCO}_{2}=$ arterial carbon dioxide partial pressure; $\mathrm{PvCO}_{2}=$ venous carbon dioxide partial pressure; $\mathrm{PvCO}_{2}-\mathrm{PaCO}_{2}=$ venous-arterial carbon dioxide partial pressure difference; $\mathrm{SvO}_{2}=$ mixed venous saturation; $\mathrm{NS}=$ nonsignificant. ${ }^{*} \mathrm{P}<0.05$ compared to the time when the patient was awake; ${ }^{+} \mathrm{P}<0.05$ compared to the time after intubation (one-way ANOVA for repeated measures). 
was $3 \pm 2 \%(27 \pm 19 \mathrm{~g})$ of the entire lung weight, poorly aerated lung parenchyma weight was $24 \pm 5 \%$ (201 \pm 58 $\mathrm{g})$, and normally aerated lung parenchyma weight was 72 $\pm 6 \%(617 \pm 133 \mathrm{~g})$.

A $17 \%$ reduction of overall lung volume was observed on the first postoperative day compared to preoperative CT $(P=0.007)$, as shown in Figure 3. This decrease was secondary to a $31 \%$ reduction in gas volume $(P<0.001)$ while tissue volume increased by $19 \%(P<0.001)$. As shown in Figure 4, there was a $19 \%$ increase in the lung parenchyma weight $(P<0.0001)$. The postoperative distribution of lung parenchyma according to aeration changed significantly from the preoperative $\mathrm{CT}$, with a significant increase in the weight of the non-aerated lung parenchyma compartment to $253 \pm 97 \mathrm{~g}(\mathrm{P}<0.001)$. This increase of collapsed lung tissue was observed in all 18 patients studied and corresponded to $27 \%$ of the weight of the entire lung parenchyma (Figure 4). Poorly aerated parenchyma presented a small but significant increase of $72 \pm 68 \mathrm{~g}(\mathrm{P}<0.001)$, corresponding to $27 \%$ of the lung. On the other hand, the weight of the normally aerated compartment decreased $147 \pm 119 \mathrm{~g}$ compared to preoperative lung CT evaluation $(P<0.001)$, with this compartment corresponding to $46 \%$ of the entire lung parenchyma.

\section{Correlations between changes in lung morphology, gas exchanges and CPB length}

No correlations were found between CPB length or the duration of surgery and the fall in $\mathrm{PaO}_{2} / \mathrm{FiO}_{2}$ ratio at the end of CPB or $24 \mathrm{~h}$ postoperatively. Neither the amount of non-aerated lung parenchyma in postoperative CT nor the increase in lung tissue were correlated to CPB length.

Asignificant negative correlation was found between the percent decrease in gas fraction (percent decrease in functional residual capacity, FRC) computed as the difference between the preoperative and postoperative gas fraction and the variation in parenchyma with decreased aeration (percent increase in the poorly aerated plus non-aerated parenchyma compartment), as shown in Figure 5. Neither non-aerated tissue parenchyma variation nor poorly aerated tissue parenchyma weight variation were independently correlated with the decrease in FRC.

No correlations were found between the $\mathrm{PaO}_{2} / \mathrm{FiO}_{2}$ ratio at $24 \mathrm{~h}$ postoperatively and the increase in non-aerated lung parenchyma weight, the decrease in normally aerated lung parenchyma weight, the variation in lung parenchyma

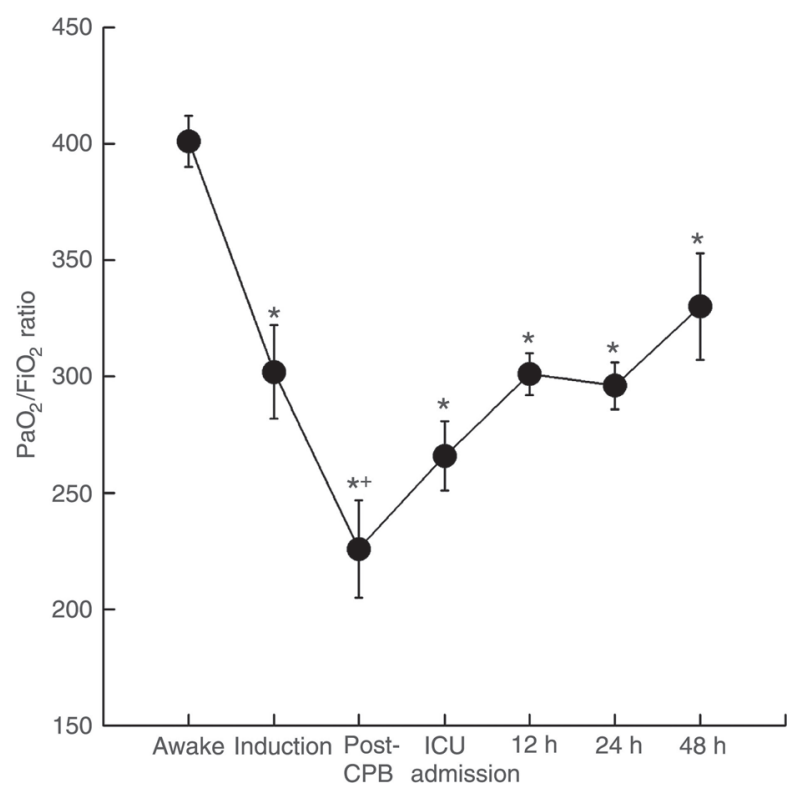

Figure 1. Behavior of the $\mathrm{PaO}_{2} / \mathrm{FiO}_{2}$ ratio (arterial partial pressure of oxygen/inspired oxygen fraction) throughout the study period. Data are reported as means \pm SEM. CPB $=$ cardiopulmonary bypass; ICU $=$ intensive care unit. ${ }^{*} \mathrm{P}<0.05$ compared to awake moment; ${ }^{+} \mathrm{P}<0.05$ compared to induction moment (Student-Neumann-Keuls post hoc test).

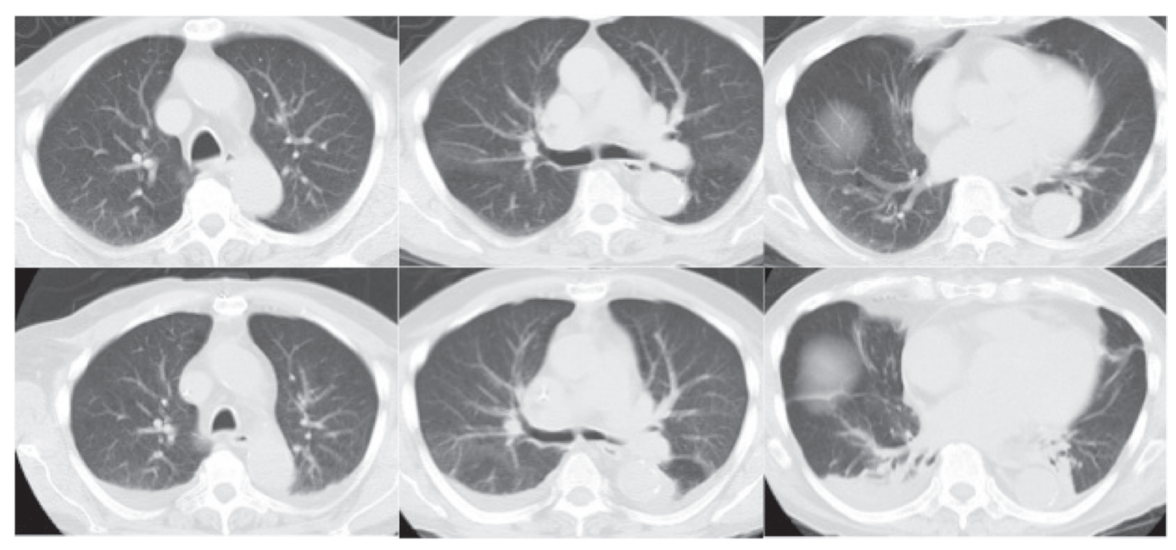

Figure 2. Representative CT slices obtained from the lung apex (left panels), pulmonary artery hilum (middle panels) and close to the diaphragm (right panels) preoperatively (upper panels) and on the first postoperative day (lower panels). 
with decreased aeration $(-500$ to $+100 \mathrm{HU})$, or the percent decrease in FRC.

\section{Discussion}

The main results of the present study were: 1) an important postoperative increase of $24 \%$ in the amount of

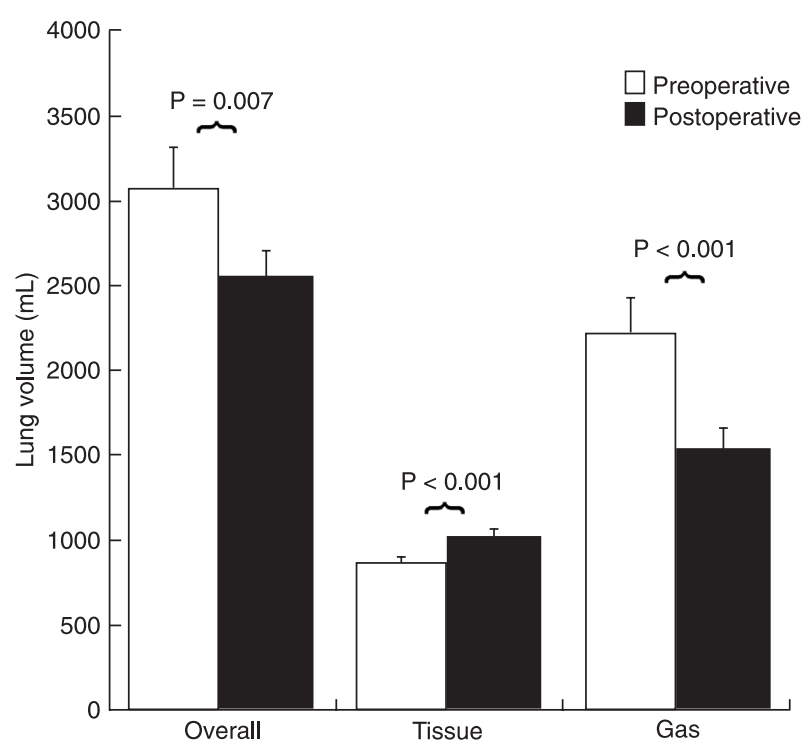

Figure 3. Overall, tissue and gas lung volumes obtained by computed tomography scans of the entire lung preoperatively (open bars) and postoperatively (filled bars). Data are reported as means + SEM and were analyzed by the paired Student $t$-test.

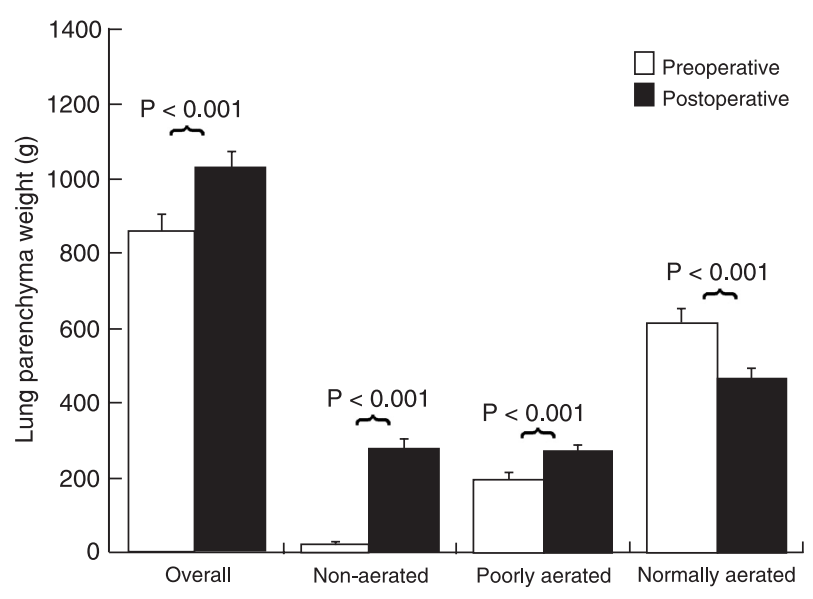

Figure 4. Overall, non-aerated, poorly aerated, and normally aerated parenchyma weight obtained from computed tomography scans of the entire lung preoperatively (open bars) and postoperatively (filled bars). Data are reported as means + SEM and were analyzed by the paired Student $t$-test. collapsed lung tissue, encompassing $27 \%$ of the lung parenchyma; 2) a significant decrease in pulmonary gas volume; 3 ) an increase in lung tissue volume (extravascular lung water), and 4) a reduction in the mass of normally aerated parenchyma. Functionally, a worsening of gas exchanges was observed intraoperatively, partially recovering within $48 \mathrm{~h}$ and was not correlated with the extension of lung atelectasis on the first postoperative day.

It is widely known that there is an impairment in pulmonary function immediately after CABG surgery (1) and persistent postoperative hypoxemia has been described as its most prevalent manifestation, even in the absence of preoperative pulmonary disease $(3,6)$. In the present study, we observed an important reduction in $\mathrm{PaO}_{2} / \mathrm{FiO}_{2}$ ratio during surgery, reaching its nadir immediately after CPB, partially recovering after $48 \mathrm{~h}$. In previous investigations, atelectasis has been consistently associated with worsening of gas exchanges after CPB in experimental or clinical contexts. In an animal model, Magnusson et al. (4) found extensive atelectasis formation after CPB, accounting for $35 \%$ of the total lung area observed in a juxtadiaphragmatic CT section, while control submitted to general anesthesia and sternotomy presented only a small amount of atelectasis (approximately 4\%). These investigators reported a good correlation between the extension of lung density and shunt fraction $\left(R^{2}=0.67\right)$. Hachenberg et al. (9) observed a sig-

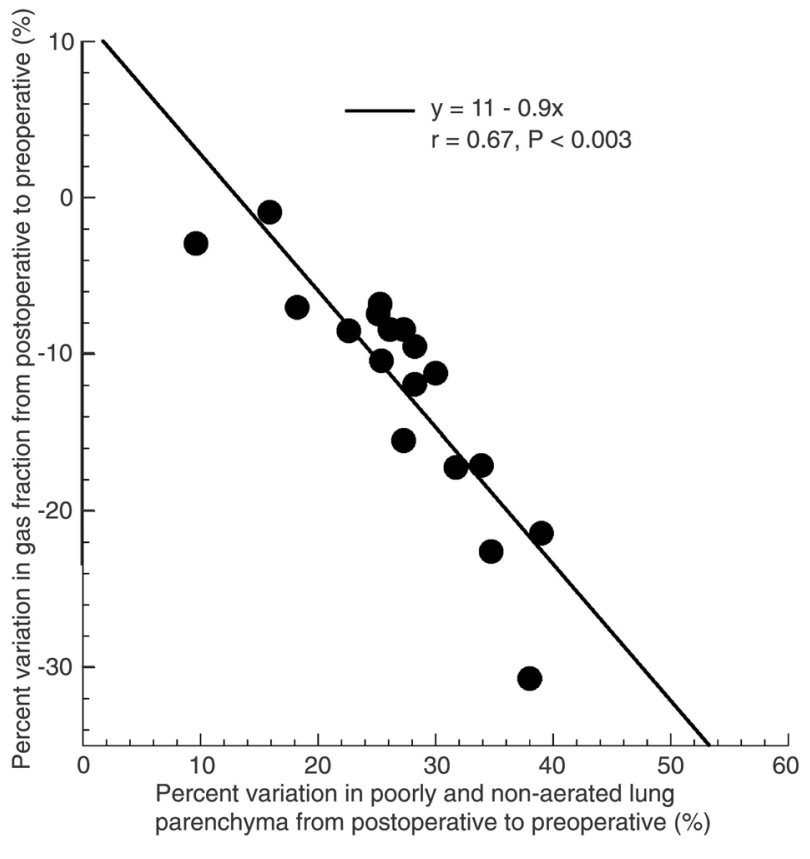

Figure 5. Correlation between the percent variation in the gas fraction and the percent variation in poorly aerated and non-aerated parenchyma from preoperative to postoperative computed tomography. Correlation was determined by linear regression analysis. 
nificant correlation ( $r=0.875)$ between the size of dense lung areas computed by CT and the intrapulmonary shunt in 11 patients with impaired respiratory function after coronary artery revascularization surgery. Conversely, Tenling et al. (10) did not correlate the extension of collapsed lung parenchyma represented in patients submitted to CABG to the magnitude of the shunt. Our results go in the same direction as those reported by Tenling et al.

Possibly, other factors are associated with postoperative worsening of gas exchanges observed in the first postoperative day in addition to the perfusion of non-aerated lung areas in this study: 1) a relative increase in the contribution of poorly aerated parenchyma (V/Q mismatch) to hypoxemia; 2) a reduction in normally aerated parenchyma, and 3) an increase in extravascular lung water.

Along with the increase in non-aerated lung parenchyma weight, there was a small increase in the mass of poorly aerated parenchyma while normally aerated parenchyma was markedly decreased. Although not correlated with the $\mathrm{PaO}_{2} / \mathrm{FiO}_{2}$ ratio at $24 \mathrm{~h}$ postoperatively, the poorly aerated lung compartment, where a low ventilation/perfusion ratio predominates instead of a true shunt, encompassed $27 \%$ of the entire lung parenchyma and might have been perfused by a considerable fraction of the cardiac output, therefore contributing to inefficient blood oxygenation. Studying awake patients after cardiac surgery, Kjaergaard et al. (14) observed that shunt values were only moderately increased and gave a minor contribution to the oxygenation problem, while low ventilation/perfusion mismatch explained the changes in postoperative oxygenation. In this study, postoperative pulmonary alterations were evaluated on the first day after surgery. At that time, patients were not receiving drugs that could hamper hypoxic pulmonary vasoconstriction (HPV). Therefore, HPV was expected to be more efficient in diverting blood flow from collapsed regions of the pulmonary parenchyma to normally and poorly aerated lung regions than during general anesthesia. Since the normally aerated parenchyma mass was reduced from 72 to $46 \%$ of the entire lung, a considerable fraction of pulmonary blood flow was expected to perfuse poorly aerated lung compartments where HPV may be less intense consequently contributing to postoperative hypoxemia.

An increase of $2.2 \pm 1.2 \mathrm{~mL} / \mathrm{kg}$ in overall lung tissue weight was observed postoperatively, probably secondary to high permeability lung edema, since all patients included in this study had normal preoperative left ventricular function and their left ventricular filling pressures were lower than $18 \mathrm{mmHg}$ throughout the study. Cardiopulmonary bypass promotes inflammation due to exposure of blood elements to the foreign surface of the oxygenator and CPB circuit (15), with subsequent trapping of activated leukocytes in the pulmonary circulation $(16,17)$. The inflammatory process is aggravated by the ischemia and reperfusion phenomenon associated with the ventilatory pause and blood flow deviation from the pulmonary circulation through the extracorporeal circuit, which results in a further increase in pulmonary endothelial permeability (18). Massoudy et al. (19) observed that extravascular lung water measured by a thermal method increased from $4.8 \pm 0.2$ to $6.7 \pm 0.4 \mathrm{~mL} / \mathrm{kg}$ for at least $4 \mathrm{~h}$ in 10 patients submitted to atrium-aortic CPB. Boldt et al. (20) found a significant but transitory increase in EVLW in CABG patients with normal left ventricular function undergoing bicaval-aortic CPB measured by means of a doubleindicator thermodilution technique with indocyanine green in ice-cold dextrose. According to these investigators, the excess of extravascular water was not observed $5 \mathrm{~h}$ after the termination of CPB. In contrast to these reports, we observed that the excess in lung tissue persisted for at least $24 \mathrm{~h}$ when the postoperative CT was obtained. These disparities between results are probably related to differences in the method used to assess EVLW, since volumetric CT analysis has been shown to be highly accurate in detecting extravascular water with a $7-g$ precision of bias (21). This inflammatory interstitial lung edema may contribute to hypoxemia by promoting collapse of subjacent regions due to increased lung parenchyma weight (22) and by increasing the distance between alveolar space and capillaries. Unfortunately, we did not detect any correlation between excess tissue and hypoxemia.

\section{Limitations of the study}

All CT scans were obtained in patients breathing spontaneously. Despite training the patients to hold their breath for $15 \mathrm{~s}$ after a normal expiration for several times before CT scan acquisition, we cannot guarantee that all images were obtained under strictly FRC conditions, with the possible induction of some bias in the analysis of gas volume and aeration distribution within the lungs. However, since most clinical studies evaluating lung CT after cardiac surgery were performed in spontaneously breathing patients and keeping patients sedated and ventilated for at least $24 \mathrm{~h}$ would be unethical and would not represent the reality, this approach seemed to be the most appropriate.

Our data show that the lung structure of patients undergoing $C A B G$ with $C P B$ is profoundly changed on the first postoperative day. Taken together, multiple changes occurring in the lungs contribute to postoperative hypoxemia rather than atelectasis alone.

\section{Acknowledgments}

Research supported by FAPESP (\#2005/0174-7). 


\section{References}

1. Kolff WJ, Effler DB, Groves LK, Hughes CR, McCormack LJ. Pulmonary complications of open-heart operations: their pathogenesis and avoidance. Cleve Clin Q 1958; 25: 65-83.

2. Asimakopoulos G, Smith PL, Ratnatunga CP, Taylor KM. Lung injury and acute respiratory distress syndrome after cardiopulmonary bypass. Ann Thorac Surg 1999; 68: $1107-$ 1115.

3. Szeles TF, Yoshinaga EM, Alenca W, Brudniewski M, Ferreira FS, Auler JO, et al. Hypoxemia after myocardial revascularization: analysis of risk factors. Rev Bras Anestesiol 2008; 58: 124-136

4. Magnusson L, Zemgulis $\mathrm{V}$, Wicky $\mathrm{S}$, Tyden $\mathrm{H}$, Thelin $\mathrm{S}$, Hedenstierna G. Atelectasis is a major cause of hypoxemia and shunt after cardiopulmonary bypass: an experimental study. Anesthesiology 1997; 87: 1153-1163.

5. Auler-Junior JO, Saldiva PH. Pulmonary structure and extravascular lung water after cardiopulmonary bypass. Braz J Med Biol Res 1986; 19: 707-714.

6. Vargas FS, Cukier A, Terra-Filho M, Hueb W, Teixeira LR, Light RW. Influence of atelectasis on pulmonary function after coronary artery bypass grafting. Chest 1993; 104: 434437.

7. Vargas FS, Terra-Filho M, Hueb W, Teixeira LR, Cukier A, Light RW. Pulmonary function after coronary artery bypass surgery. Respir Med 1997; 91: 629-633.

8. Nozawa E, Kobayashi E, Matsumoto ME, Feltrim MI, Carmona MJ, Auler JJ. Assessment of factors that influence weaning from long-term mechanical ventilation after cardiac surgery. Arq Bras Cardiol 2003; 80: 301-310.

9. Hachenberg $\mathrm{T}$, Brussel $\mathrm{T}$, Roos $\mathrm{N}$, Lenzen $\mathrm{H}$, Mollhoff $\mathrm{T}$, Gockel B, et al. Gas exchange impairment and pulmonary densities after cardiac surgery. Acta Anaesthesiol Scand 1992; 36: 800-805.

10. Tenling A, Hachenberg T, Tyden H, Wegenius G, Hedenstierna $\mathrm{G}$. Atelectasis and gas exchange after cardiac surgery. Anesthesiology 1998; 89: 371-378.

11. Hedenstierna G. Atelectasis formation and gas exchange impairment during anaesthesia. Monaldi Arch Chest Dis 1994; 49: 315-322.

12. Puybasset L, Cluzel P, Chao N, Slutsky AS, Coriat P, Rouby JJ. A computed tomography scan assessment of regional lung volume in acute lung injury. The CT Scan ARDS Study Group. Am J Respir Crit Care Med 1998; 158: 1644-1655.

13. Vieira SR, Puybasset L, Richecoeur J, Lu Q, Cluzel P, Gusman $\mathrm{PB}$, et al. A lung computed tomographic assessment of positive end-expiratory pressure-induced lung overdistension. Am J Respir Crit Care Med 1998; 158: 1571-1577.

14. Kjaergaard S, Rees SE, Gronlund J, Nielsen EM, Lambert $\mathrm{P}$, Thorgaard $\mathrm{P}$, et al. Hypoxaemia after cardiac surgery: clinical application of a model of pulmonary gas exchange. Eur J Anaesthesiol 2004; 21: 296-301.

15. de Vroege R, Rutten PM, Kalkman C, Out TA, Jansen PG, Eijsman L, et al. Biocompatibility of three different membrane oxygenators: effects on complement, neutrophil and monocyte activation. Perfusion 1997; 12: 369-375.

16. Massoudy P, Zahler S, Becker BF, Braun SL, Barankay A, Richter JA, et al. Significant leukocyte and platelet retention during pulmonary passage after declamping of the aorta in CABG patients. Eur J Med Res 1999; 4: 178-182.

17. Massoudy P, Zahler S, Becker BF, Braun SL, Barankay $\mathrm{A}$, Meisner $\mathrm{H}$. Evidence for inflammatory responses of the lungs during coronary artery bypass grafting with cardiopulmonary bypass. Chest 2001; 119: 31-36.

18. Schlensak C, Doenst T, Spillner G, Blum U, Geiger A, Beyersdorf F. Palliative treatment of a secondary aortoduodenal fistula by stent-graft placement. Thorac Cardiovasc Surg 2000; 48: 41-42.

19. Massoudy P, Piotrowski JA, van de Wal HC, Giebler R, Marggraf $G$, Peters J, et al. Perfusing and ventilating the patient's lungs during bypass ameliorates the increase in extravascular thermal volume after coronary bypass grafting. Ann Thorac Surg 2003; 76: 516-521.

20. Boldt J, Zickmann B, Dapper F, Hempelmann G. Does the technique of cardiopulmonary bypass affect lung water content? Eur J Cardiothorac Surg 1991; 5: 22-26.

21. Malbouisson LM, Preteux F, Puybasset L, Grenier P, Coriat $\mathrm{P}$, Rouby JJ. Validation of a software designed for computed tomographic (CT) measurement of lung water. Intensive Care Med 2001; 27: 602-608.

22. Pelosi P, D'Andrea L, Vitale G, Pesenti A, Gattinoni L. Vertical gradient of regional lung inflation in adult respiratory distress syndrome. Am J Respir Crit Care Med 1994; 149: 8-13. 